\title{
Effect of palm oil mill effluent supplementation on cellulase production from rice straw by local fungal isolates
}

\begin{abstract}
In this study, Palm Oil Mill Effluent (POME) was selected as supplement in rice straw fermentation to replace commercial inducer due to its high concentration of simple carbohydrate and nitrogenous compounds. The cellulase activity of the enzyme produced were then determined individually and combined (enzyme cocktail) to observe increment in cellulase activity. Individually, filter paperase (FPAse), carboxymethyl cellulase (CMCase) and $\beta$-glucosidase activities increase for all 3 fungi used except FPAse for Aspergillus sp. (NEW). Highest FPAse and CMCase activities increment observed was from Phanerochaete chrysosporium which were 72 and 236\% increment, respectively, while highest $\beta$-glucosidase activity was from Aspergillus terreus (AT) which was $298 \%$ increment. Meanwhile in cocktail cellulase, synergistic effect was observed especially for FPAse activity whereby highest FPAse activity observed was by cocktail of all the three species of fungi which show 393\% increment. Though CMCase increment was observed in this mode, it was not as high as FPAse where the highest CMCase activity observed was cocktail by the three fungal species which increased by $41 \%$. However, in $\beta$-glucosidase activity, only cocktail of NEW and AT showed increment from their average activity which was by $6 \%$. It seems that $\beta$ glucosidase activity plays major role in determining the total cellulase activity. In the nutshell, supplementation of POME can improve cellulase activity.
\end{abstract}

Keyword: Cellulase; Enzyme cocktail; Rice straw; Fungi; Supplement 